\title{
“ALTO LÁ”: A CONSTRUCIONALIZAÇÃO DE UM MARCADOR DISCURSIVO NA LÍNGUA PORTUGUESA
}

\author{
“ALTO LÁ”: THE CONSTRUCTIONALIZATION OF A DISCOURSE MARKER \\ IN THE PORTUGUESE LANGUAGE
}

\author{
Flávia Saboya da Luz Rosa | Lattes | flaviasaboya@gmail.com \\ Universidade Federal Fluminense
}

Mariangela Rios de Oliveira | Lattes | mariangelariosdeoliveira@gmail.com Universidade Federal Fluminense | Universidade do Estado do Rio de Janeiro

Resumo: Investigamos neste artigo a trajetória que leva alto lá a se convencionalizar como membro da classe dos marcadores discursivos do português, em subfunção refreador-argumentativa. Adotando a Linguística Funcional Centrada no Uso, nos termos de Traugott e Trousdale (2013), Bybee (2010; 2015) e Hilpert (2014), entre outros, identificamos três motivações distintas que concorrem para a construcionalização de alto lá: a) as histórico-sociais, devido à origem bélica do termo alto; b) as cognitivas, relativas à conceptualização metafórica DISCUSSÃO É GUERRA, de acordo com Lakoff e Johnson (2003); c) as estruturais, que se referem tanto ao cline contextual, conforme Diewald e Smirnova (2012), em que se registram os micropassos que conduzem à construcionalização de alto lá como marcador discursivo, como também as de base analógica, em consonância com Bybee (2010) e Fischer (2009), por meio das quais alto lá, via melhor encaixe, é fixada a partir do esquema já formado por elemento indutor e afixoide locativo Concluímos que, uma vez convencionalizada como microconstrução, [alto lá] ${ }_{\mathrm{RA}}$ concorre para reconfiguração do esquema $\left[\mathrm{V}_{\text {indut }} \mathrm{Afix}_{\mathrm{Loc}}\right]_{\mathrm{MD}}$ que passa a ser codificado como [Indut Afix $\mathrm{Loc}_{\mathrm{MD}}$. Devido a essa reconfiguração, novos links são criados em que não só verbos, como também frases nominais, advérbios, entre outros, caracterizados como indutores, passam a compor a subparte nuclear da construção. A investigação tem viés pancrônico, conjugando abordagem diacrônica e sincrônica, partindo de análise qualitativa e quantitativa.

Palavras-chave: Construcionalização gramatical. Marcação discursiva. Neoanálise. Analogização. 
Abstract: We investigate in this article the path that leads alto lá to become conventionalized as a member of the class of Portuguese discourse markers, in restraining argumentative subfunction. Following the Usage-based Language, in terms of Traugott and Trousdale (2013), Bybee $(2010 ; 2015)$ and Hilpert (2014), among others, we identify three distinct motivations that contribute to the constructionalization of alto lá: a) the historical-social, due to the war origin of the term alto; $b$ ) the cognitive ones, related to the metaphorical conceptualization ARGUMENT IS WAR, according to Lakoff and Johnson (2003); c) the structural ones, which refer to both the contextual cline, according to Diewald and Smirnova (2012), which record the microsteps leading to the constructionalization of alto lá as a discourse marker, as well as the analogical base ones, in line with Bybee (2010) and Fischer (2009), whereby alto lá, via a better fit, is fixed from the scheme already formed by inductive element and locative affixoid. We conclude that, once conventionalized as microconstruction, the [alto lá $]_{\mathrm{RA}}$ contributes to reconfigure the scheme $\left[\mathrm{V}_{\text {indut }} A \mathrm{Afix}_{\mathrm{Loc}}\right]_{\mathrm{MD}}$, which is now codified as [Indut $\left.\mathrm{Afix}_{\mathrm{Loc}}\right]_{\mathrm{MD}}$. Due to this reconfiguration, new links are created in which not only verbs, but also nominal phrases, adverbs, among others, characterized as inductors, become part of the nuclear subpart of the construction. The investigation has a panchronic bias, combining a diachronic and synchronic approach, based on qualitative and quantitative analysis.

Keywords: Grammatical constructionalization. Discourse marking. Neoanalysis. Analogization.

\section{INTRODUÇÃO}

Neste artigo, nos dedicamos à investigação de como se processou a convencionalização da expressão alto lá na gramática do português, por intermédio de sua inserção no paradigma dos marcadores discursivos (doravante $\mathrm{MD}$ ), conforme as propriedades dessa categoria apontadas por Heine, Kaltenböck e Kuteva (2019). De acordo com esses autores, os MD compõem um paradigma que partilha, ao menos, quatro traços prototípicos: (a) invariabilidade formal; (b) autonomia sintática; (c) prosódia específica; (d) função de relacionar um enunciado à situação do discurso, isto é, relacionar quanto à organização dos textos, à interação entre falante e ouvinte e/ou às atitudes do falante.

Com base nos resultados de Rosa (2019), assumimos que [alto lá ${ }_{\mathrm{MD}}$ constitui uma microconstrução gramatical, um $\mathrm{MD}$ que atua na subfunção de refreamento argumentativo (doravante RA), integrante do constructicon ${ }^{1}$ do português, tal como instanciada no fragmento (1):

\footnotetext{
1 Termo oriundo do Cognitivismo, mais especificamente da abordagem construcional da gramática, na referência à rede estruturada e hierárquica de construções de uma língua.
} 
(1) [... ] salvou galhardamente a vida das garras de uma onça e é motivo de sobra para que eu lhe seja eternamente agradecida, e creio que também para que o primo não abocanhe e não despreze assim um homem, que não lhe fez mal algum. - Nenhum mal.. eu sei. e também que me importa a mim esse homem. Ou por sim, ou por não, amanhã ou depois, logo que ele possa montar a cavalo, hei de levá-lo para minha casa, porque é nosso hóspede, e meu tio nenhuma obrigação tem de aguentá-lo. -Alto lá, primo! - atalhou Paulina com vivacidade; - menos essa.. temos muito mais obrigação do que o senhor, e havemos de aguentá-lo com muito prazer. Enquanto não sarar de todo, ele é nosso, e não arreda pé daqui. - Isso era bem belo. e a mulada dele que lá fica à toa.. não hei de ser eu que hei de tomar conta dela. (Corpus do Português: Histórias e tradições da província de Minas Gerais, de Bernardo Guimarães, 1872).

No fragmento (1), o emprego de alto lá exprime, como MD, o conteúdo mais específico de refrear a proposição enunciada pelo primo de Paulina: logo que ele possa montar a cavalo, hei de levá-lo para minha casa, porque é nosso hóspede, e meu tio nenhuma obrigação tem de aguentá-lo. Paulina, então, utiliza a construção refreadora para introduzir a sua posição contrária ao que foi dito menos essa e, em seguida, apresentar sua refutação temos muito mais obrigação do que o senhor, e havemos de aguentá-lo com muito prazer. Enquanto não sarar de todo, ele é nosso, e não arreda pé daqui. Em contextos como o ilustrado em (1), alto lá apresenta suas subpartes fortemente vinculadas, em termos de sentido e forma; a subparte nuclear alto, integrada ao afixoide lá, já não expressa referência ao mundo biossocial, formando um todo, em pareamento de forma e função, que aponta exclusivamente para o âmbito pragmático-discursivo. Nesse fragmento, alto lá constitui uma só unidade de sentido e forma, funcionando como MD no refreamento argumentativo.

Consideramos que [alto lá $]_{\mathrm{RA}}$, instanciado em contextos como em (1), constitui um type específico forjado na língua por intermédio de uma série de neonálises, ou seja, por um conjunto de micropassos a partir dos quais os usuários reelaboraram e reinterpretaram sentidos, de modo inédito e inovador, conforme Andersen (2001) e também por mecanismos analógicos, como defendem Traugott e Trousdale (2013) e Fischer (2009). Assumimos que, na trajetória de alto lá rumo ao paradigma dos $\mathrm{MD}$, contribuíram os seguintes fatores: a) a conjuntura histórica, uma vez que a subparte inicial desse pareamento (alto) constitui originalmente um comando utilizado em exercícios e combates de 
infantaria; b) o compartilhamento sociocultural da metáfora conceptual DISCUSSÃO É GUERRA (LAKOFF; JOHNSON, 2003); c) o cline contextual de crescente integração semântico-sintática, como previsto por Diewald e Smirnova (2012); d) a analogização, por meio do melhor encaixe, com um padrão construcional de $\mathrm{MD}$ formado inicialmente por verbo e locativo, $\left[\mathrm{V}_{\text {indut }} A \mathrm{Afix}_{\mathrm{Loc}}\right]_{\mathrm{MD}}$, convencionalizado no português a partir da construcionalização de vem cá no século XVI, como demonstrado em Teixeira (2015).

Nesse sentido, nossos objetivos neste artigo são: a) investigar a origem militar do termo alto na língua portuguesa e a conjuntura histórica dessa sincronia; b) refletir sobre conceitos e associações culturalmente compartilhados envolvendo a arte de argumentar e as ações hierárquicas e linguísticas no âmbito de guerra; c) verificar a trajetória de mudança de alto em micropassos contextuais para sua vinculação ao afixoide ${ }^{2}$ lá, bem como examinar em que condições se deu a analogização de alto lá ao esquema $\left[\mathrm{V}_{\text {indut }} \mathrm{Afix}_{\mathrm{Loc}}\right]_{\mathrm{MD}}$. Adotamos os fundamentos teóricos da Linguística Funcional Centrada no Uso (doravante LFCU), nos termos de Traugott e Trousdale (2013), Bybee (2010; 2015) e Hilpert (2014), entre outros. Esse arcabouço resulta da incorporação da abordagem construcional da gramática (CROFT, 2001; GOLDBERG, 1995; 2006; 2019) à pesquisa de orientação funcionalista de vertente norte-americana, como praticada por Givón, Hopper e Heine, por exemplo. De acordo com tal concepção, os usos linguísticos são motivados, ao menos, por pressões de três naturezas distintas: as formais, atinentes à configuração estrutural da gramática; as cognitivas, referentes aos processos de domínio geral (BYBEE, 2010) que moldam as interações; as pragmático-discursivas, relativas aos fatores de ordem histórico-social e contextual que emolduram os usos linguísticos. No Brasil, tal viés mais recente dos estudos funcionalistas se encontra em Rosário e Oliveira (2016), Oliveira e Cezario (2017), entre outras fontes.

Trabalhamos com perspectiva pancrônica de análise, combinando viés sincrônico e diacrônico. A pesquisa no recorte sincrônico contemporâneo, referente aos séculos XX e XXI, foi realizada com base no acervo digital de publicações dos diários do Congresso Nacional, que é composto pela Câmara dos Deputados e pelo Senado Federal. Os corpora para o estudo diacrônico, envolvendo textos dos séculos XIII ao XX, foram formados por meio dos acervos do Corpus do Português ${ }^{3}$ e do Corpus Histórico do Português Tycho Brahe 4 . O Corpus do Português é constituído de mais de 45 milhões de palavras provenientes de aproximadamente 57.000 textos. São contabilizadas 20 milhões de palavras do

\footnotetext{
${ }^{2}$ De acordo com Booij (2013), consideramos afixoide uma categoria gradiente, situada no intervalo entre termos lexicais, de conteúdo mais pleno, como nomes e verbos, e termos de maior sentido procedural, de conteúdo abstrato, como afixos e desinências. Nesse sentido, a subparte periférica da construção aqui estudada (lá) é assumida como afixoide.

${ }^{3}$ Disponível em: https://www.corpusdoportugues.org/

${ }^{4}$ Disponível em: https://www. http://www.tycho.iel.unicamp.br/corpus/
} 
século XX, 10 milhões do século XIX, e 15 milhões de palavras dos séculos XIII-XVIII. No século XX, o corpus contém seis milhões de palavras de ficção, seis milhões de jornais e revistas, seis milhões de textos acadêmicos e dois milhões de textos orais. Para cada um desses quatro gêneros e, portanto, na sua totalidade, os textos do século XX estão igualmente divididos entre textos de Portugal e do Brasil. Com uma composição mais modesta, quando comparado ao anteriormente citado, o Corpus Tycho Brahe apresenta 76 textos, em que se encontram 3.302.666 palavras.

Metodologicamente, combinamos abordagem qualitativa e quantitativa. Em termos qualitativos, adotamos a proposta de Diewald (2002; 2006) e Diewald e Smirnova (2012), para analisar interpretativamente as propriedades que emolduram e motivam a convencionalização do MD [alto lá $]_{\mathrm{RA}}$. A abordagem quantitativa, por sua vez, concorre para avaliar a fixação e a produtividade dessa convencionalização na história da língua, como postulam Bybee (2010; 2015) e Traugott e Trousdale (2013), entre outros.

Este artigo se encontra dividido em quatro seções. Na primeira, apresentamos as bases teóricas da LFCU que apoiam as análises, com foco na abordagem construcional da gramática e nos contextos de uso que motivam mudança linguística. Na segunda seção, analisamos a trajetória de alto lá na história do português, desde o uso mais referencial de alto, atinente ao universo militar português da Idade Moderna, passando por sucessivas neoanálises, até chegar à atuação de $\mathrm{MD}$, com o ingresso de alto lá nessa categoria gramatical. Na terceira seção, demonstramos como tal trajetória é responsável pela reconfiguração da rede de $\mathrm{MD}$ do português formada inicialmente pelo esquema $\left[\mathrm{V}_{\text {indut }} \mathrm{Afix}_{\mathrm{Loc}}\right]_{\mathrm{MD}^{\prime}}$ como apontado por Teixeira (2015), com destaque para o mecanismo de analogização atuante também nesse processo. Por fim, tecemos algumas considerações, a partir dos resultados obtidos.

\section{BASES TEÓRICAS DA LFCU}

A LFCU, nos termos em que é assumida por Traugott e Trousdale (2013), Bybee (2010; 2015) e Hilpert (2014), é considerada a versão atual do Funcionalismo praticado originalmente nos Estados Unidos, a partir da incorporação do tratamento construcional da gramática, oriundo do Cognitivismo. Para apresentarmos os fundamentos teóricos assim concebidos, esta seção se encontra distribuída em duas subseções: uma que trata do aparato construcional e outra que se volta para os contextos de uso e consequente mudança linguística.

\subsection{Construção: definição e propriedades}

A abordagem construcionista da mudança linguística que nos interessa se encontra basicamente em Traugott e Trousdale (2013). Na visão desses autores, e também na de 
pesquisadores cognitivistas, como Goldberg (2006) e Langacker (2008), em um modelo assim concebido, a língua é composta por pareamentos forma-conteúdo ${ }^{5}$, também chamados de construções, organizados em rede. Assim posto, conforme Hilpert (2014) e Goldberg (2019), conhecer e usar uma língua é conhecer e instanciar pareamentos convencionalizados dessa língua, é conhecer e lidar com o constructicon, ou seja, com a rede complexa e dinâmica das construções que integram a gramática, entendida esta em sentido lato.

Como apontam Traugott e Trousdale (2013), a mudança linguística se dá por construcionalização ou por mudanças construcionais. A construcionalização é a criação de uma associação forma ${ }_{\text {nova }}$-conteúdo ${ }_{\text {novo }}$ ou seja, é o desenvolvimento de uma nova unidade ou novo nó na rede. A construcionalização forma novos tipos de nós que têm nova sintaxe ou morfologia e novo conteúdo codificado na rede linguística de uma população de falantes. Já as mudanças construcionais, que, por hipótese, precedem e possibilitam a construcionalização, envolvem tipicamente expansão pragmática, semantização dessa pragmática, mismatch entre forma e conteúdo e algumas pequenas mudanças distributivas.

Dos modelos construcionistas de esquematização forma-conteúdo, um dos mais clássicos é o de Croft (2001, p. 18), ilustrado conforme nossa adaptação a seguir:

Figura 1: Modelo para a estrutura simbólica de uma construção.

\begin{tabular}{|c|c|}
\hline \multicolumn{2}{|c|}{ CONSTRUÇÃO_ } \\
\hline \multicolumn{2}{|l|}{ Propriedades sintáticas } \\
\hline Propriedades morfológicas & FORMA \\
\hline \multicolumn{2}{|l|}{ Propriedades fonológicas } \\
\hline \multicolumn{2}{|c|}{$\mid \leftarrow$ ELO DE CORRESPONDÊNCIA SIMBÓLICA } \\
\hline \multicolumn{2}{|l|}{ Propriedades semânticas } \\
\hline Propriedades pragmáticas & CONTEÚDO \\
\hline Propriedades discursivo-fun & \\
\hline
\end{tabular}

Fonte: Adaptado de Croft, 2001, p. 18.

Como podemos observar pela Figura 1, propriedades relativas à forma, como as sintáticas, as morfológicas e as fonológicas, se encontram vinculadas, por elo de correspondência simbólica, a propriedades de conteúdo, distribuídas em semânticas, pragmáti- 
cas e discursivo-funcionais. A partir desse modelo, aplicamos, também, nossa proposta da nomenclatura forma-conteúdo (ROSA, 2019) numa adaptação à representação de construção apresentada por Traugott e Trousdale (2013, p.8): [[Forma] <---> [Conteúdo]], em que a seta bidirecional especifica a relação biunívoca entre forma e conteúdo, e os colchetes externos, um indicador de que o pareamento é uma unidade convencionalizada.

Se consideramos alto lá uma microconstrução, porquanto é totalmente especificada, então podemos codificá-la como [alto lá $]_{\mathrm{RA}}$, associando suas propriedades formais e de conteúdo de modo estrito. $\mathrm{O}$ mesmo comentário interpretativo que fizemos na introdução, com o fragmento (1), fazemos a seguir, com outro dado do corpus:

(2) - Senhor Miguel, continuou em voz alta, entregando-lhe a carteira, - guarde por ora o seu dinheiro; Isaura não me pertence ainda; só meu pai pode dispor dela. Meu pai acha-se na corte, e não deixou-me autorização alguma para tratar de semelhante negócio. Arranje-se com ele. - Mas V. S. é seu filho e herdeiro único, e bem podia por si mesmo... - Alto lá, senhor Miguel! meu pai felizmente é vivo ainda, e não me é permitido desde já dispor de seus bens, como minha herança. (A Escrava Isaura, de Bernardo Guimarães, 1875).

Em (2), como podemos observar, alto lá se encontra altamente vinculado, em termos de forma e conteúdo, iniciando discurso direto, antecedendo vocativo. Funciona como membro da classe dos $\mathrm{MD}$, em subfunção de refreamento argumentativo, em contexto marcado por forte intersubjetividade e emotividade, levando o interlocutor a inferências, como postulado por Traugott e Dasher (2005). Trata-se de uma só unidade de forma e conteúdo, cujas propriedades devem ser identificadas em termos dessa forte vinculação.

Para Traugott e Trousdale (2013), os pareamentos forma-conteúdo podem ser pensados em termos de várias dimensões, todas gradientes. Entre tais dimensões, estão a extensão, o grau de especificidade fonológica e o tipo de conteúdo veiculado. Nesse sentido, respectivamente, podemos classificar [alto lá $]_{\mathrm{RA}}$ como: a) complexa, porque é formada por duas subpartes; b) substancial, porque se configura como type específico, totalmente preenchido em suas subpartes; c) procedural, porque veicula conteúdo gramatical, voltado para a marcação do discurso, no nível pragmático.

Traugott e Trousdale (2013) apresentam ainda três fatores bastante relevantes para análise da arquitetura das construções: esquematicidade, produtividade e composicionalidade. A esquematicidade é a propriedade de categorização que envolve necessariamente 
abstração e a que mais nos interessa nesta subseção. Um esquema é uma generalização taxonômica de categorias, seja linguística ou não. Sendo assim, entendemos que esquemas são abstrações por meio das quais grupos de construções (inconscientemente) assimiladas pelos usuários da língua relacionam-se estreitamente em rede. Neste artigo, optamos por trabalhar com as ideias de macro e mesoconstruções, conforme postulado em Traugott (2008), por entendermos que estas dão conta do pareamento forma-conteúdo definidor das construções. Por essa razão, adotamos as seguintes definições de Traugott (2008, p. 236):

Macroconstruções: pareamentos de forma-conteúdo que são definidos por estrutura e função. Em nosso estudo, é representada pela macroconstrução marcadora discursiva, formada por elemento indutor seguido de afixoide: [Indut Afix $]_{\mathrm{MD}}$

Mesoconstruções: conjuntos de construções específicas de comportamento similar. Neste artigo, nosso foco recai sobre a mesoconstrução marcadora discursiva refreador-argumentativa, formada por elemento indutor-refreador seguido de afixoide de origem locativa: $\left[\text { Indut }_{\mathrm{R}} \mathrm{Afix}_{\mathrm{Loc}}\right]_{\mathrm{RA}}$

Microconstruções: tipos individuais de construção, como nosso objeto de pesquisa [alto lá $]_{\mathrm{RA}}$

Construtos: tokens empiricamente atestados, que são o locus da mudança, como as instâncias de uso destacadas nos fragmentos (1) e (2)

Na compatibilização dessas definições de Traugott (2008) com a hierarquia proposta por Oliveira e Arena (2019), partimos do seguinte cline esquemático:

Quadro 1: Pareamento forma-conteúdo na hierarquia construcional

\begin{tabular}{|c|c|c|}
\hline \multirow{2}{*}{$\begin{array}{c}\text { Hierarquia } \\
\text { construcional }\end{array}$} & Forma & Conteúdo \\
\cline { 2 - 3 } & Pareamento \\
\hline Macroconstrução & estrutura abrangente & função \\
\hline Mesoconstrução & estrutura delimitada & subfunção \\
\hline Microconstrução & estrutura específica & significado \\
\hline Constructo & estrutura substancial & sentido \\
\hline
\end{tabular}

Fonte: Rosa (2019, p. 46).

Ao relacionar a hierarquia construcional com nosso objeto de pesquisa, em movimento de baixo para cima, podemos dizer que: a) alto lá é instanciado, no uso, como um 
constructo, com sentido contextualmente especificado, conforme interpretamos em (1) e (2); b) esse constructo licencia a microconstrução [alto lá $]_{\mathrm{RA}}$, cujo significado convencionalizado é fruto da forte vinculação das subpartes alto e lá, que formam um todo de conteúdo e forma; c) a microconstrução [alto lá] é membro da família RA, cuja subfunção é refrear a proposição do interlocutor e apoiar a argumentação do enunciador; d) essa família, por sua vez, pertence a um grupo funcional e esquemático mais alto e amplo, formado pela classe dos MD que se esquematizam por subparte indutora e elemento afixoide.

Outro fundamento teórico relevante no que concerne à abordagem construcional assumida pela LFCU que aqui nos interessa é a analogização, nos termos em que é tratada por Traugott e Trousdale (2013). Segundo esses autores, trata-se de um mecanismo de mudança, um tipo especial de neoanálise fundada na formação de pareamentos inovadores a partir de outros mais esquemáticos que lhes servem de modelo. A analogização, tomada por Bybee (2010) como um dos principais processos cognitivos de domínio geral, impacta o constructicon e reforça a concepção de que aprender uma língua é conhecer as construções que a formam. Assim, novas microconstruções, como [alto lá] ${ }_{\mathrm{RA}}$, são muitas vezes motivadas também por pensamento analógico, no nosso caso, via a macroconstrução $[\text { Indut Afix }]_{\mathrm{MD} \text {. }}$

\subsection{Contextos de mudança e estágio de paradigmatização}

Consideramos que a mudança linguística não afeta itens isoladamente, mas incide sobre porções maiores do contexto de uso. Tais porções, além de serem afetadas como um todo, também acabam por motivar novas mudanças. Assim, consideramos fundamental o olhar mais acurado sobre as propriedades contextuais em que alto e lá são instanciados, adotando aqui a proposta taxonômica de Diewald e Smirnova $(2012)^{6}$, que, por sua vez, é o refinamento das versões iniciais de Diewald (2002; 2006).

De acordo com as referidas autoras, os micropassos da mudança pelos quais passam os elementos linguísticos podem ser captados e classificados em termos de estágios contextuais de crescente vinculação de forma e conteúdo. Essas alterações se iniciam no plano do conteúdo (contexto atípico), por intermédio de polissemias ou inferências contextuais, atingem posteriormente o plano da forma (contexto crítico), quando ocorre re-

\footnotetext{
${ }^{6}$ Elaborada originalmente para dar conta da gramaticalização, adotamos essa taxonomia por entender que a construcionalização gramatical, abordagem teórica assumida neste artigo, abarca a gramaticalização. Tratase, portanto, de modelos compatíveis.
} 
organização estrutural, e chegam ao estágio de convencionalização (contexto isolado), em que se efetiva a mudança linguística (em nossos termos, a construcionalização). A etapa final (integração paradigmática) contempla a entrada do novo membro em classe gramatical da língua, passando a competir com os demais membros dessa classe pela instanciação no uso linguístico. O Quadro 2 ilustra e sintetiza nosso comentário:

Quadro 2: Tipos de contextos em construcionalização gramatical

\begin{tabular}{|l|l|l|l|}
\hline \multicolumn{1}{|c|}{ Estágio } & \multicolumn{1}{|c|}{ Contexto } & \multicolumn{1}{c|}{ Características } & \multicolumn{1}{c|}{$\begin{array}{c}\text { Tipos de } \\
\text { construção }\end{array}$} \\
\hline $\begin{array}{l}\text { I- Precondiçães da } \\
\text { construcionalização } \\
\text { gramatical }\end{array}$ & $\begin{array}{l}\text { Contexto } \\
\text { atípico }\end{array}$ & Implicaturas conversacionais & $\begin{array}{l}\text { Sem tipo particular de } \\
\text { construção; } \\
\text { composicional }\end{array}$ \\
\hline $\begin{array}{l}\text { II- Desencadeamento } \\
\text { da construcionalização } \\
\text { gramatical }\end{array}$ & $\begin{array}{l}\text { Contexto } \\
\text { crítico }\end{array}$ & Opacidade múltipla & $\begin{array}{l}\text { Expressões } \\
\text { idiomáticas } \\
\text { extragramaticais }\end{array}$ \\
\hline $\begin{array}{l}\text { III- Reorganização e } \\
\text { diferenciação }\end{array}$ & $\begin{array}{l}\text { Contexto } \\
\text { isolado }\end{array}$ & $\begin{array}{l}\text { Itens polissêmicos/ } \\
\text { heterossêmicos }\end{array}$ & $\begin{array}{l}\text { Expressões } \\
\text { idiomáticas formal ou } \\
\text { lexicalmente abertas }\end{array}$ \\
\hline $\begin{array}{l}\text { IV- Integração } \\
\text { paradigmática }\end{array}$ & $\begin{array}{l}\text { Contexto } \\
\text { paradigmático }\end{array}$ & $\begin{array}{l}\text { Oposições/distinções } \\
\text { paradigmáticas com significados } \\
\text { relacionais reduzidos, isto é, } \\
\text { significados gramaticais }\end{array}$ & $\begin{array}{l}\text { Escolhas } \\
\text { paradigmáticas a } \\
\text { partir de um esquema } \\
\text { construcional abstrato }\end{array}$ \\
\hline
\end{tabular}

Fonte: Rosa (2019, p. 64), adaptado de Diewald e Smirnova (2012).

O Quadro 2, por intermédio dos quatro estágios contextuais elencados, aponta as etapas pelas quais passam os constituintes linguísticos rumo à mudança gramatical. $\mathrm{Na}$ verdade, o quarto estágio não é uma etapa de alterações ao nível sintagmático, mas sim constitui o ponto de inserção de um novo elemento na gramática; dito em termos construcionais, equivale à entrada de um novo nó no constructicon.

\section{A TRAJETÓRIA DE [ALTO LÁ $]_{\mathrm{RA}}$ NO PORTUGUÊS}

Para tratarmos das distintas motivações e das etapas que conduziram à convencionalização de [alto lá $]_{\mathrm{RA}}$ como microconstrução instanciada pela macroconstrução [Indut Afix $]_{\mathrm{MD}}$, concorrendo para a reconfiguração desse esquema maior, esta seção se encontra dividida em três partes. Na primeira, nos dedicamos aos fatores de natureza pragmática, atinentes à conjuntura histórica, que concorreram para que a subparte nuclear alto fosse eleita e fixada pela comunidade linguística como candidata à convencionalização gramatical que forjou [alto lá $]_{\mathrm{RA}}$. Na segunda, nos dedicamos à conceptualização metafórica 
DISCUSSÃO É GUERRA, que atuou como mais um fator a concorrer para o estabelecimento de [alto lá $]_{\mathrm{RA}}$. Por fim, na terceira parte, apresentamos e analisamos, em termos qualitativos e quantitativos, o cline contextual, que, na história da língua, via neoanálises sucessivas, deu origem à construção estudada.

\subsection{Etimologia e contexto histórico}

Na LFCU, conforme apresentamos na introdução deste artigo, um dos tripés motivadores do uso linguístico e de sua convencionalização é de ordem discursivo-pragmática, incluindo-se neste conjunto os fatores histórico-sociais. Assim, tratamos aqui do que justifica a seleção de alto, subparte nuclear da microconstrução estudada, na trajetória do português, para a formação de um membro da classe dos MD.

A origem desse termo como comando adotado em exercícios e combates de infantaria é atestada em Bluteau (1716). Segundo o autor, há duas hipóteses para a origem de alto com o sentido de parar, ambas relacionadas ao contexto bélico: uma relacionada ao ato de fincar a bandeira ou estandarte em posição elevada sinalizando interrupção de marcha, e outra correspondente a uma adaptação em português da forma halt, imperativo do verbo alemão halten (parar). Uma ou outra dessas acepções são encontradas e abonadas também em outras fontes.

Destacamos que alto é detectado em nosso corpus a partir do séc XVII, de acordo com o sentido referido, instanciado em comentários acerca do universo militar português durante a Idade Moderna. É importante destacar que as ações de guerra lusitanas, devido ao lançamento e manutenção do império no Brasil, causaram impacto de diversas naturezas na região, inclusive cultural e linguístico. Constatamos que o uso do termo na língua portuguesa iniciou-se em âmbito militar com o sentido de realização de parada da marcha da tropa, a partir da análise empírica que empreendemos. É importante ter em vista que, quando se fala a respeito desse uso em contextos narrativo ou descritivo, a expressão utilizada é fazer alto (alto = substantivo), com as devidas variações flexionais do verbo fazer de acordo com o tempo e modo empregados, conforme o fragmento (3). No entanto, quando há interação dialógica, em que o locutor comunica-se com seu(s) interlocutor(es) ou consigo mesmo, valendo-se de sequências enunciativas ou argumentativas, a expressão usada é alto! ( alto = frase nominal interjetiva), como consta em (4): 
(3) Armado de Iesvs em o peito, e gola, / Alto fará, com sua infanteria, / No meyo da Cidade o graó Loyola /Num Templo, que do Céo tem a Armaria, /O Guiaõ que da Fée nelle tremola /Descobre, de Iesvs a Companhia, /Onde com clara lux de entendimento /Fará Ignaçio, hum firme alojamento. (Corpus do Português: Insulana, de Manoel Thomas, 1625).

(4) Quando dá a voz de fogo é sempre contra o palácio! [...]. Nisto, do fundo do largo, elevou-se uma voz aguda e estridente, gritando: - Às armas! Era o João da tropa. Marchou em passo acelerado até defronte do palácio, onde estacou à voz de - alto! - Depois, com grandes gestos, ia executando sucessivamente as vozes que berrava - carregar! apontar! fogo! - Vestido com uma velha fardeta de soldado, esfrangalhada e a cair aos farrapos, com uma calça remendada listrada de trapos vermelhos e com um chapéu armado de papel na cabeça, segurava na mão uma cana, trazendo outra mais pequena pendente da cinta à laia de baioneta. Com a sua comprida barba e o olhar incerto de doido, tinha um ar estranhamente fantástico! (Corpus do Português: O segredo da minha cadeirinha, de Conde de Arnoso, 1886).

Apresentamos na Tabela 1 o quantitativo ${ }^{7}$ de alguns arranjos formados com o termo alto, seja como substantivo, associado a flexões do verbo fazer, seja como interjeição, seguida por pronome locativo/afixoide locativo. Ao observar os dados, é possível perceber a concentração de registros no século XIX, época subsequente ao boom literário com temática de guerra ocorrido nos quase 300 anos anteriores. No que diz respeito à expressão fazer alto, os números referentes ao seu emprego nos tempos do pretérito do indicativo (27/49) e no infinitivo (14/49) conformam-se aos modos de organização textual narrativo e descritivo. Não por acaso, esses modos de organização textual são característicos, respectivamente, de obras memoriais e instrucionais, preponderantes na produção literária bélica:

\footnotetext{
${ }^{7}$ Não foram encontrados registros das expressões alto e fazer alto do século XIII ao XVI no Corpus do Português e do XIV ao XVIII no Corpus Tycho Brahe.
} 
Tabela 1: Expressões envolvendo o termo alto nos corpora

\begin{tabular}{|c|c|c|c|c|c|c|c|}
\hline $\begin{array}{l}\text { Categorias } \\
\text { da língua }\end{array}$ & Arranjos & $\begin{array}{l}\text { Séc. } \\
\text { XVII } \\
\end{array}$ & $\begin{array}{l}\text { Séc. } \\
\text { XVIII }\end{array}$ & $\begin{array}{l}\text { Séc. } \\
\text { XIX }\end{array}$ & $\begin{array}{l}\text { Séc. } \\
\text { XX } \\
\end{array}$ & $\begin{array}{l}\text { Séc. } \\
\text { XXI }\end{array}$ & Total \\
\hline \multirow{14}{*}{$\begin{array}{l}\text { alto como } \\
\text { substantivo: } \\
\text { fazer alto }\end{array}$} & fazer alto & 02 & ${ }^{*} 01$ & 08 & 02 & - & 13 \\
\hline & fazerem alto & - & ${ }^{*} 01$ & - & - & - & 01 \\
\hline & fazendo alto & - & - & 02 & - & - & 02 \\
\hline & feito alto & 01 & - & - & - & - & 01 \\
\hline & fazem alto & - & - & 01 & - & - & 01 \\
\hline & fazia alto & - & - & - & 01 & - & 01 \\
\hline & fez alto & 01 & ${ }^{*} 01$ & 09 & 05 & - & 16 \\
\hline & fizemos alto & - & - & 01 & 01 & - & 02 \\
\hline & fizeram alto & - & 01 & 01 & 03 & - & 05 \\
\hline & fizera alto & - & - & - & 03 & - & 03 \\
\hline & faça alto & - & - & 01 & - & - & 01 \\
\hline & fizéssemos alto & - & - & 01 & - & - & 01 \\
\hline & fizessem alto & - & - & - & 01 & - & 01 \\
\hline & alto fará & 01 & - & - & - & - & 01 \\
\hline \multicolumn{2}{|l|}{ Subtotal } & 05 & 04 & 24 & 16 & - & 49 \\
\hline \multirow{3}{*}{$\begin{array}{l}\text { alto como } \\
\text { interjeição: } \\
\text { alto! }\end{array}$} & alto aqui & - & - & 01 & - & - & 01 \\
\hline & alto aí & - & - & 02 & 02 & - & 04 \\
\hline & alto lá & - & - & 46 & 20 & 99 & 165 \\
\hline \multicolumn{2}{|l|}{ Subtotal } & - & - & 49 & 22 & 99 & 170 \\
\hline \multicolumn{2}{|l|}{ Total } & 05 & 04 & 73 & 38 & 99 & 219 \\
\hline
\end{tabular}

Fonte: Rosa (2019, p. 80/81).

Conforme detectamos na Tabela 1, o uso de alto como substantivo tem registro mais antigo e menos produtivo no corpus, com 49 dados gerais, levantados a partir do século XVII. Alto como interjeição, já em arranjos mais vinculados, é levantado do século XIX em diante, com produtividade maior, totalizando 170 ocorrências. Desses usos interjetivos, destaca-se alto lá, com 165 registros.

De acordo com Bybee $(2010 ; 2015)$, consideramos que a frequência de uso impacta a representação cognitiva, portanto, a recorrência maior de alto lá acaba por formar um chunking, um pareamento mais convencionalizado de forma e conteúdo que vai sendo fixado na representação linguística da comunidade, dando origem a um novo constituinte da gramática. Nesse sentido, consideramos que a história do uso de alto e sua crescente vinculação ao locativo lá ilustra como o contexto histórico-social, enquanto fator de natureza pragmática, pode impactar a convencionalização gramatical.

\subsection{A metáfora conceptual DISCUSSÃO É GUERRA}

Além do fator de ordem histórico-social, relativo à origem bélica da parte nuclear de [alto lá $]_{\mathrm{RA}}$, documentada nas fontes bibliográficas do português, e do cline contextu- 
al apresentado na subseção seguinte, identificamos outra motivação relevante para essa mudança linguística. Estamos nos referindo ao processo cognitivo de transferência metafórica, conforme postulado por Lakoff e Johnson (2003), segundo o qual a discussão é tomada como atividade bélica.

É relevante constatar que o uso das expressões alto e alto lá faz parte de uma conceptualização cultural, em que um fenômeno, a discussão, é praticado, compreendido e descrito em termos de outro, a guerra. No português do Brasil, o termo discussão apresenta, basicamente, três acepções diferenciadas e metonimicamente relacionadas: bate-boca, debate e polêmica. $\mathrm{O}$ modo argumentativo de organização discursiva está intimamente associado à acepção de debate (conferência), que pode ser permeado por controvérsia (polêmica) e até mesmo resultar em altercação (bate-boca). Sob um olhar mais específico, com foco na argumentação, constituinte dos debates, constatamos haver paralelismo entre os mecanismos argumentativos e as investidas entre os beligerantes: proposição (ataque), justificação (defesa), refutação (contra-ataque), ponderação (espécie de trégua). Essa metáfora conceptual, vivenciada em tantas culturas como a nossa, é espelhada na linguagem cotidiana por uma ampla variedade de expressões, como, por exemplo:

- Suas reivindicações são indefensáveis.

- Ele atacou todos os pontos fracos do meu argumento.

- Suas críticas foram certeiras.

- Eu destruí o argumento dele.

- Eu nunca ganhei uma discussão com ele.

- Você discorda? Então, manda bala!

- Se você usar essa estratégia, ele vai acabar com você.

- Ele derrubou todos os meus argumentos.

(LAKOFF; JOHNSON, 2003, p. 5. Tradução nossa)

Para esses autores, é importante observar que não apenas falamos de discussão em termos de guerra, mas também entendemos que realmente ganhamos ou perdemos discussões; vemos a pessoa com quem estamos discutindo como um oponente; atacamos suas posições e defendemos as nossas; planejamos e usamos estratégias; abandonamos posições indefensáveis e tomamos nova linha de ataque etc. Discussões e guerras são tipos diferentes de eventos - discurso verbal e conflito armado - e as ações praticadas são diferentes em cada um deles. No entanto, a primeira é parcialmente compreendida, executada e abordada em termos da segunda, ou seja, o conceito, a atividade e, conse- 
quentemente, a linguagem referentes à discussão (e por conseguinte à argumentação) são metaforicamente estruturados por meio da noção de guerra.

Vejamos um exemplo de nosso corpus, cujas expressões destacadas e numeradas são referidas na Figura 2. As relações metafóricas, metonímicas ou analógicas específicas das expressões em destaque não serão aqui desenvolvidas em prol da observação maior sobre a metáfora conceptual e o englobamento da expressão alto:

(5) - Nego! exclamou formidavelmente o cônego que em sua casa, à sua mesa, punha de alto as suas opiniões. - E nego com os meus autores. Eles aí vão! E deixou-lhe cair em cima, como penedos(1) de autoridade, os nomes venerados de Laboranti, Baldeschi, Merati, Turrino e Pavônio. Amaro afastara a cadeira, pusera-se em atitude de controvérsia, contente de poder, diante de Amélia, "enterrar"(2) o cônego, mestre de teologia moral e um colosso de liturgia prática. - Sustento, exclamou, sustento com Castaldus... - Alto(3), ladrão(4), bramiu o cônego. Castaldus é meu! - Castaldus é meu, padre-mestre! E encarniçaram-se(5), puxando cada um para si(6) o venerável Castaldus e a autoridade da sua facúndia. D. Josefa pulava de gozo na cadeira, murmurando para Amélia com a cara franzida de riso: - Ai, que gostinho vê-los! Ai, que santos! (Corpus do Português: O Crime do Padre Amaro, de Eça de Queirós, 1875).

Figura 2: Domínios fonte e alvo na metáfora conceptual DISCUSSÃO É GUERRA no exemplo (5)

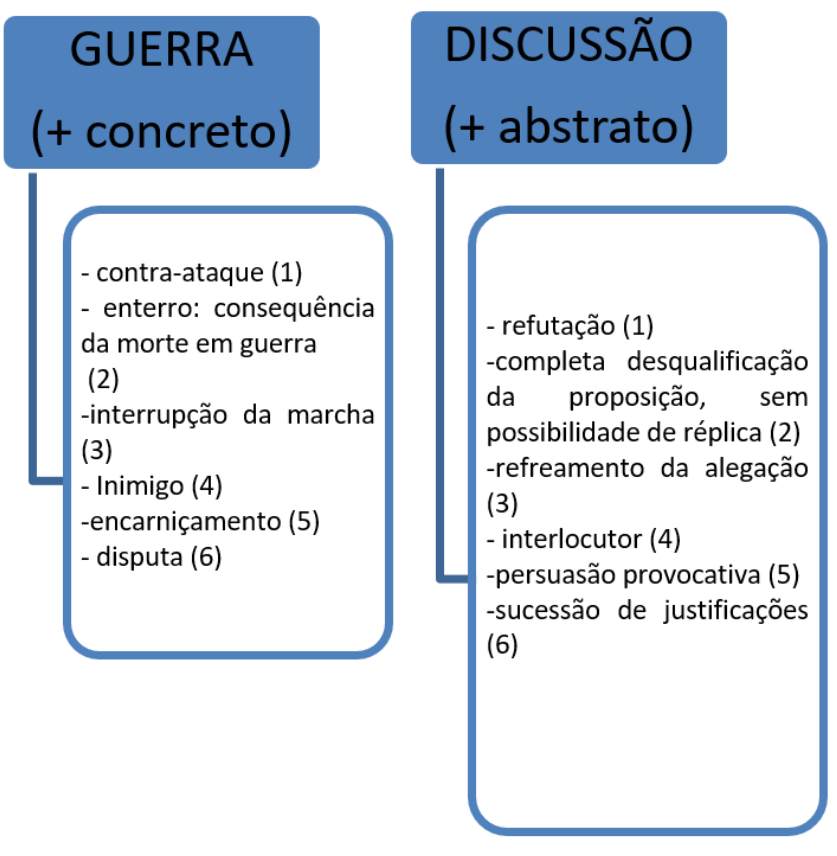

Fonte: Rosa (2019, p. 102). 
O uso de alto, em (5), retrata o emprego do que, originalmente, seria o comando de interrupção de marcha da tropa, atividade essa situada no mundo biossocial. Essa referência, mais concreta, serve, por meio de mecanismos metafóricos, a uma prática mais abstrata, situada no campo discursivo: o refreamento - no fragmento (5), trata-se de interrupção propriamente dita -, da justificação do locutor. É preciso atentar para o fato de que, ao proferir a palavra de ordem alto, o enunciador não só se vale da linguagem metafórica como também executa uma ação metaforicamente estruturada. Ele se apropria da autoridade de um comandante para determinar a cessação da alegação alheia, munindo-se de uma espécie de patente habilitada pela detenção e convicção da verdade.

Portanto, entendemos que a metáfora conceptual DISCUSSÃO É GUERRA licencia o uso do comando alto, e, por conseguinte, alto lá, no domínio discursivo. Essa transferência de domínios concorre como mais um aspecto motivador da construcionalização [alto lá $]_{\mathrm{RA}}$.

\subsection{Cline contextual}

Nesta subseção, apresentamos e analisamos os estágios contextuais, conforme identificados no Quadro 2, que deram origem a [alto lá $]_{\mathrm{RA}}$ na trajetória do português, a partir de 165 dados da expressão alto lá levantados em nosso corpus, de acordo com a Tabela 2, na sequência. Trazemos a distribuição da expressão alto lá a partir de três fatores: a) o período de sua ocorrência no corpus (séculos XIX, XX e XXI); b) o estágio contextual em que é instanciada (atípico, crítico e isolado); c) a comparação com os demais arranjos com os quais compete (alto aí e alto aqui):

Tabela 2: Quantitativo de alto Loc/Afix nos contextos de mudança

\begin{tabular}{|l|l|l|l|l|l|l|l|l|l|l|l|l|}
\hline Contextos & Atípico & \multicolumn{4}{l|}{ Crítico } & \multicolumn{3}{l|}{ Isolado } & \multicolumn{2}{l|}{ Subtotal } & \multirow{2}{*}{ Total } \\
\hline Séculos & XIX & XX & XIX & XX & XIX & XX & XXI & XIX & XX & XXI & \\
\hline alto aí & 01 & - & - & 02 & 01 & - & - & 02 & 02 & - & 04 \\
\hline alto aqui & 01 & - & - & - & - & - & - & 01 & - & - & 01 \\
\hline alto lá & 05 & 02 & 09 & - & 32 & 18 & 99 & 46 & 20 & 99 & 165 \\
\hline Subtotal & 07 & 02 & 09 & 02 & 33 & 18 & 99 & 49 & 22 & 99 & \\
\hline Total & 09 & 11 & 150 & & & & & 170 \\
\hline
\end{tabular}

Fonte: Rosa (2019, p. 82).

Nas subseções seguintes, vamos utilizar os dados quantitativos da Tabela 2 nos comentários analíticos das etapas contextuais da mudança linguística aqui estudada. Esta 
apresentação se inicia pelo contexto atípico, na consideração de que o contexto original de uso reside na instanciação do termo alto como elemento composicional, ou seja, com transparência entre forma e conteúdo lexical, tal como ilustrado em (3) e (4), ainda sem relação com pronome locativo.

\subsubsection{Contexto atípico}

De acordo com a caracterização referida no Quadro 2, esse estágio contextual é o primeiro passo rumo a uma possível mudança gramatical. Nesse ambiente, começam a se processar alterações ao nível do sentido, com polissemias e articulação de inferências contextuais. Há ocorrência de expansão inespecífica de usos em novos arranjos não previstos, que implicam sentidos mais subjetivos.

Em nosso corpus, conforme destacado na Tabela 2, dos 165 dados gerais de alto lá, sete constituem contextos atípicos, sendo cinco detectados no século XIX e dois no século XX, como no seguinte fragmento:

(6) Nada... nada de reflexões, continuou sorrindo-se; mãe Sara (permita que lhe chame assim), dê-me uma xícara do seu café e metade do seu pão... eu já estou bom... completamente bom... e sinto uma fome terrível... ah... então parece que duvidam... pois, meus bons amigos, eu não faço cerimônia... com licença. E dizendo isto o moço serviu-se de café e pão, e começou a fazer boa companhia aos seus hóspedes; já se dispunha a repetir segunda dose de café, quando a velha o suspendeu. - Alto lá, senhor! Não se come tanto de uma vez ao entrar em convalescença.. - Também acho-lhe razão, mãe Sara, e sujeito-me agora a suas determinações; porém, ali pelo correr das duas horas há de fazer-me o favor de servir-me com uma... está bem, não vamos tão depressa; com metade de uma galinha ensopada, guisada, assada, ou como lhe parecer. É certo que agora não tenho dinheiro, porém amanhã, mãe Sara, eu lhe prometo que há de ser paga $[\ldots]$.

(Corpus do Português: O moço loiro, de Joaquim Manuel de Macedo, 1845).

Em (6), observamos que o termo alto, que aparece vinculado ao afixoide lá, é empregado em âmbito civil, num episódio em que pessoas tomam café da manhã num determinado estabelecimento. $O$ protagonista da cena, que já havia se servido de café e pão, é interrompido ao tentar repetir a dose da bebida: Alto lá, senhor! Não se come tanto 
de uma vez ao entrar em convalescença. Visto que se trata de um contexto diferente do original, o consideramos como atípico. Nesse fragmento, constatamos o uso da expressão já existente, alto, em combinação incomum, alto lá, quando comparada ao contexto fonte. Apesar do surgimento da nova forma, o significado mais amplo de refreamento de uma atividade desenvolve-se a partir do contexto de origem, não mais restrito ao sentido de suspensão da marcha da tropa, mas expandido à cessação de outras práticas para além do cenário militar. Em se tratando da composicionalidade de alto lá, ainda que haja transparência parcial no significado do elemento nuclear, alto, advindo da permanência das relações biossociais, é possível perceber que não há referência espacial por meio do lá, que constitui uma subparte da expressão dependente sintática e semanticamente do núcleo, caracterizando-se como afixoide. Comparada aos usos originais de alto e de lá, a expressão alto lá é considerada menos composicional, devido à transparência parcial do núcleo e à vinculação da subparte afixoide.

No século XIX, como demonstrado na Tabela 2, levantamos um dado de contexto de uso atípico envolvendo, respectivamente, alto aí e alto aqui, o que evidencia a fase inicial, e, portanto, ainda instável, da mudança em curso. Acreditamos que a emergência da unidade sintático-semântica alto lá tenha sido licenciada pela esquematização de [alto aí] em analogia à macroconstrução $\left[\mathrm{V}_{\text {indut }} \mathrm{Afix}_{\mathrm{Loc}}\right]_{\mathrm{MD}}$. Com o surgimento de forma nova e desenvolvimento do significado mais amplo a partir do original - o que constitui certa permanência semântica -, entendemos ter havido, do primeiro ao segundo estágio, mudança construcional, nas definições de Traugott e Trousdale (2013).

\subsubsection{Contexto crítico}

Esse estágio contextual, considerado por Diewald e Smirnova (2012) como etapa de transição mais avançada para a efetivação da mudança linguística, é detectado em nove dados, todos levantados no século XIX, entre os 165 usos da expressão alto lá que compõem nosso corpus. A Tabela 2 registra ainda dois usos de alto aí nesse estágio contextual.

Para além de ambiguidades ao nível do conteúdo, o contexto crítico se caracteriza por opacidade ao nível da forma, em que se confundem margens estruturais, com o licenciamento de novas interpretações, entre as quais figura o novo significado a ser fixado em etapa posterior. De acordo com Diewald (2002, 2006), o contexto crítico deflagra o efetivo processo de construcionalização, nos termos de Traugott e Trousdale (2013). Segundo a autora, nesse estágio, surgem novas expressões que não podem ser reduzidas a uma combinação de construções conhecidas sem perda de informação, como verificamos em (7): 
(7) Era ali o sumptuoso gabinete de leitura e música de D. Ifigénia. Ornavam as paredes dois retratos a corpo inteiro: Calisto Elói com a farda de fidalgo cavaleiro, e Ifigénia trajada de amazona... - Olha o meu marido! - clamou Teodora. - Aquela é a tal mulher? - perguntou à espantada Tomásia. - Aquela é a Sr.a D. Ifigénia. - Vou rasgar aquele diabo! - berrou a morgada, arrastando uma cadeira para trepar. - Isso alto lá, minha senhora! - acudiu irada a despenseira. - V. Ex.a não estraga coisa nenhuma. E, se continua nesse disparate, eu mando chamar o cabo da rua para a pôr lá fora. - Pôr-me a mim lá fora! - bradou Teodora. - Sim, minha senhora, que isto não são termos. Nem me parece senhora! Cá em Lisboa acções destas só as praticam as peixeiras. (Corpus do Português: A queda dum anjo, de Camilo Castelo Branco, 1866).

No fragmento (7), o emprego da expressão alto lá apresenta, ao menos, duas possibilidades de interpretação. Na primeira, captamos o significado desenvolvido no contexto atípico: interrupção de atividade. O narrador da história explica que, ao anunciar que rasgaria o mencionado retrato, Teodora arrasta uma cadeira para nela subir e concretizar o ato. Logo, o uso de alto lá pela despenseira pode apresentar o sentido de suspender o movimento de sua interlocutora de subir na cadeira para alcançar o retrato e então rasgá-lo. O que permite essa leitura é o conhecimento da conjuntura conversacional, nesse caso específico, a informação dada pelo autor de que Teodora estava arrastando uma cadeira para trepar. Sob essa ótica, o uso de alto lá estaria relacionado a cessar uma atividade praticada no mundo biossocial, conforme foi observado nos contextos anteriores.

De outra parte, é possível realizar uma análise diferente. A segunda interpretação fornece a ideia de que o emprego de alto lá pode estar associado não à ação de Teodora, mas ao seu enunciado Vou rasgar aquele diabo!. Assim, o significado da construção não mais expressaria interrupção de atividade/prática do mundo biossocial, passando a exprimir o refreamento de uma proposição, que antecede sua refutação $V$. Ex.a não estraga coisa nenhuma. E, se continua nesse disparate, eu mando chamar o cabo da rua para a pôr lá fora. Desse modo, a atuação da microconstrução estaria relacionada ao âmbito discursivo. A anteposição do pronome demonstrativo isso à expressão alto lá parece favorecer tal interpretação, por assemelhar-se a características de construções mais cristalizadas como isso é o que veremos e afins, em que isso aponta para o enunciado anteriormente produzido. No entanto, se ainda há possibilidade de leitura semelhante ao contexto anterior, ou seja, relacionada à interrupção de atividade do mundo biossocial, em que isso se refere ao 
movimento direcionado à destruição do retrato, então, o contexto em questão não pode ser considerado único, isolado.

Nesse sentido, entendemos que o constructo em foco pertence a contexto crítico pelos seguintes motivos: observamos haver ambiguidade no uso de alto lá em (7), pois o sentido parece se relacionar tanto ao refreamento da ação de arrastar uma cadeira para nela subir e estragar o retrato quanto ao refreamento da afirmação Vou rasgar aquele diabo!; além disso, a segunda leitura fornece o novo significado de refreamento-argumentativo da construção, estritamente ligado ao discurso, que será tratado adiante no contexto isolado.

\subsubsection{Contexto isolado}

Esse estágio contextual, considerado etapa de consolidação da mudança linguística, é caracterizado pelo isolamento, ou distinção, de conteúdo e de forma dos itens em relação a seu status mais antigo, de natureza lexical. Em termos construcionais, conforme Traugott e Trousdale (2013) e Hilpert (2014), consideramos que nessa etapa se efetiva a construcionalização gramatical [alto lá $]_{\mathrm{RA}}$, uma vez que se convencionaliza o chunking de ambas as subpartes, em prol de um só conteúdo e de um só formato, com a criação de um novo type na rede gramatical.

Conforme aponta a Tabela 2, dos 165 dados coletados em nosso corpus envolvendo a expressão alto lá, 149 constituem exemplares de contexto isolado, em que se instancia [alto lá $]_{\mathrm{RA}}$. Trata-se, portanto, de evidência que destaca a produtividade dessa microconstrução. Outro resultado relevante é que, dos 149 dados de uso como MD, 32 ocorrem no século XIX, 18 no século XX e 99 no século XXI, o que evidencia, de outra parte, a maior frequência de [alto lá $]_{\mathrm{RA}}$ em contextos de uso mais recente da língua. Estamos nos referindo a dados como o seguinte:

(8) O Sr. Gilvan Borges (PMDB - AP.) Há pessoas que vêm da Europa ou da América do Norte e chegam ao nosso País dizendo que o Brasil é ruim. Alto lá! Somos um País jovem buscando e trabalhando nosso próprio caminho. Que País belo e maravilhoso! Aqui, de quatro em quatro anos, renovam-se suas forças políticas, buscando alternativas e soluções! (Diário do Congresso Nacional (Seção II), 29 abril de 1995). 
No fragmento (8), temos a reprodução da fala do parlamentar Gilvan Borges, que debate, em forte tom emocional e intersubjetivo, acerca do que considera uma visão preconceituosa de pessoas estrangeiras que chegam ao Brasil. O político primeiramente apresenta a proposição de europeus e norte-americanos recém-chegados ao nosso país: o Brasil é ruim, para, logo em seguida, refrear argumentativamente tal declaração com o MD alto lá! Na sequência, a fim de refutar a proposição citada, expõe seus argumentos, destacando a juventude e a beleza nacionais. Assim articulado, o constructo alto lá! concorre para imprimir a todo o contexto a marca da argumentação, mais especificamente, no que concerne à refutação do comentário inicial; trata-se de um pareamento altamente vinculado que funciona no nível pragmático-discursivo, na articulação interativa entre os interlocutores.

\subsubsection{Contexto paradigmático}

Diewald e Smirnova (2012) entendem por integração paradigmática o processo de estabilização de um novo signo construcionalizado que o transforma em parte integral de um paradigma. A nova construção passa a ser confrontada com membros em oposição do mesmo padrão, sendo gradualmente associada com um significado gramatical mais abstrato, que serve como um denominador comum para todo o paradigma.

A partir da construcionalização de [alto lá ${ }_{\mathrm{RA}}$, isto é, do pareamento da nova forma e do novo significado, há estabilização da construção no paradigma dos $\mathrm{MD}$ no $\mathrm{PB}$, mais precisamente, formados por elementos indutores e afixoides. Nessa relação, há oposições/distinções paradigmáticas, isto é, variabilidade de significados gramaticais (neste caso específico, discursivo-funcionais), que podem ser selecionados, um em detrimento de outros, a partir de uma macroconstrução.

Segundo as mesmas autoras, no que se refere às características formais, os membros de um paradigma podem mostrar variação. Assumimos que [alto lá $]_{\mathrm{RA}}$ entra no paradigma como um elemento marginal, com preenchimento não verbal, mas nominal em uso interjetivo, da subparte nuclear da construção. Contudo, as subpartes verbais dos membros mais centrais do paradigma apresentam formas, quase sempre, fixas, sendo mais raras as construções propensas a variações fonológicas ou flexionais, como por exemplo, olha aí e olhe aí. Sendo assim, a propriedade invariável da frase nominal interjetiva alto, enquadra-se, grosso modo, com certa homogeneidade, a características formais do paradigma.

Apresentamos, no quadro seguinte, os traços paradigmáticos de [Indut $\mathrm{Afix}]_{\mathrm{MD}^{\prime}}$ com destaque para [alto lá $]_{\mathrm{RA}}$ : 
Quadro 3: Integração paradigmática da microconstrução alto lá ${ }^{8}$

\begin{tabular}{|l|l|l|l|}
\hline Rótulo da categoria: & Marcadores discursivos \\
\hline Características formais: & Formados por elementos indutores seguidos de afixoides \\
\hline Função: & Marcação discursiva & \multicolumn{2}{|l|}{} \\
\hline $\begin{array}{l}\text { Exemplos de distinções } \\
\text { discursivo-funcionais: }\end{array}$ & Refreamento-Argumentativo & Exortação & Chamamento de atenção $^{8}$ \\
\hline Exemplos de membros: & alto lá & vamos lá & escuta aqui, olha aí, vê lá \\
\hline
\end{tabular}

Fonte: Rosa (2019, p. 100), adaptado de Diewald e Smirnova (2012, p. 128).

O Quadro 3 ilustra a inserção de [alto lá $]_{\mathrm{RA}}$ no paradigma dos MD formados por elementos indutores e afixoides, vinculada a uma subfunção distinta daquelas a que estão associadas as microconstruções exortativas e de chamamento de atenção. É importante ressaltar que, devido à amplitude do paradigma, optamos por selecionar duas distinções discursivo-funcionais dentro desse padrão, contudo, esclarecemos que as subfunções dos $\mathrm{MD}$ formados por elementos indutores e afixoides não se limitam as aqui exemplificadas.

\section{3 [ALTO LÁ $]_{\mathrm{RA}}$ E A RECONFIGURAÇÃO DA REDE [INDUT AFIX $]_{\mathrm{MD}}$}

Conforme a análise desenvolvida na seção anterior, a inserção de [alto lá ${ }_{\mathrm{RA}}$ como um type específico da macroconstrução [Indut $\mathrm{Afix}]_{\mathrm{MD}}$ é resultante de um conjunto de fatores de natureza diversa e em atuação na língua em momentos distintos. Esses fatores vão ao encontro do que preconiza a LFCU, nos termos de Traugott e Trousdale (2013), Bybee (2010; 2015) e Hilpert (2014), entre outros, no sentido de se conceber o constructicon como uma rede sistêmica, complexa e dinâmica, fundada em três pilares fundamentais, como mencionamos na parte introdutória deste capítulo.

Assim posto, consideramos como motivação de ordem sócio-histórica a conjuntura dos séculos XVI a XVIII, em que Portugal se dedica fortemente às guerras, havendo grande difusão da literatura de temática bélica e, consequentemente, dos termos a ela intrínsecos. Em termos cognitivos, assumimos que o compartilhamento sociocultural da metáfora conceptual DISCUSSÃO É GUERRA impacta e concorre para a convencionalização do chunking [alto lá $]_{\mathrm{RA}}$.

Do ponto de vista estrutural, apontamos duas pressões complementares. Uma delas identificada com o conjunto de neoanálises, por meio de micropassos ao longo dos contextos de mudança, que resultaram em contextos atípicos, críticos e finalmente iso-

\footnotetext{
8 Teixeira (2015) apresenta funções específicas para cada uma das microconstruções desse subgrupo. Aqui, optamos por reuni-las, pois entendemos que compartilham um traço formal comum, constituição da subparte nuclear por verbos perceptivos, e uma função mais abrangente, o chamamento de atenção.
} 
lados. Esses ambientes textuais mais amplos concorreram para a convencionalização de [alto lá $]_{\mathrm{RA}}$ e sua inserção no paradigma dos MD do português.

Por outro lado, assumimos que a construcionalização [alto lá $]_{\mathrm{RA}}$ é resultante também de um tipo particular de neonálise, a analogização, conforme assumida por Fischer (2009) e Traugott e Trousdale (2013). De acordo com esses autores, uma vez estabelecido um esquema na língua, este fica disponível para, de forma modelar, ser usado com vistas a replicar o padrão, num tipo de mudança linguística mais instantânea e situada, motivada por pensamento analógico, um dos processos cognitivos de domínio geral, nos termos de Bybee (2010). No caso de nosso objeto de pesquisa, verificamos a analogização de [alto lá $]_{\mathrm{RA}}$ com características formais e de conteúdo da família $\left[\mathrm{V}_{\text {indut }} \mathrm{Afix}_{\mathrm{Loc}}\right]_{\mathrm{MD}}$ por meio do melhor encaixe

Assim, a rota contextual que leva à construcionalização de [alto lá $]_{\mathrm{RA}}$ se encontra com outro tipo de neoanálise na história da língua, a analogização à macroconstrução licenciada por [vem cá $]_{\mathrm{MD}}$, convencionalizada desde o século XVI, conforme aponta Teixeira (2015). Esse type, em movimento bottom-up, fornece a base de conteúdo e forma que forja a macroconstrução MD esquematizada por verbo indutor e afixoide locativo $\left[\mathrm{V}_{\text {indut }} \mathrm{Afix}_{\mathrm{Loc}}\right]_{\mathrm{MD}}$. Concluímos que, no século XIX, a construcionalização de alto lá ocorre por meio do melhor encaixe com algumas características dessa macroconstrução. Uma vez sancionada, a partir de propriedades de $\left[\mathrm{V}_{\text {indut }} \mathrm{Afix}_{\mathrm{Loc}}\right]_{\mathrm{MD}}$, a microconstrução alto lá é replicada e fixada em comunidades linguísticas. Por conseguinte, os falantes passam a realizar novo processamento bottom-up. Logo, se estabelece a macroconstrução reconfigurada [Indut Afix $]_{\mathrm{MD}}$, ampliando a instanciação de microconstruções formadas por outros tipos de elementos nucleares indutores, antes restritos ao verbos Com a Figura 3, ilustramos o comentário:

Figura 3: Micropassos contextuais e analogização na trajetória de alto a [alto lá $]_{\mathrm{RA}}$

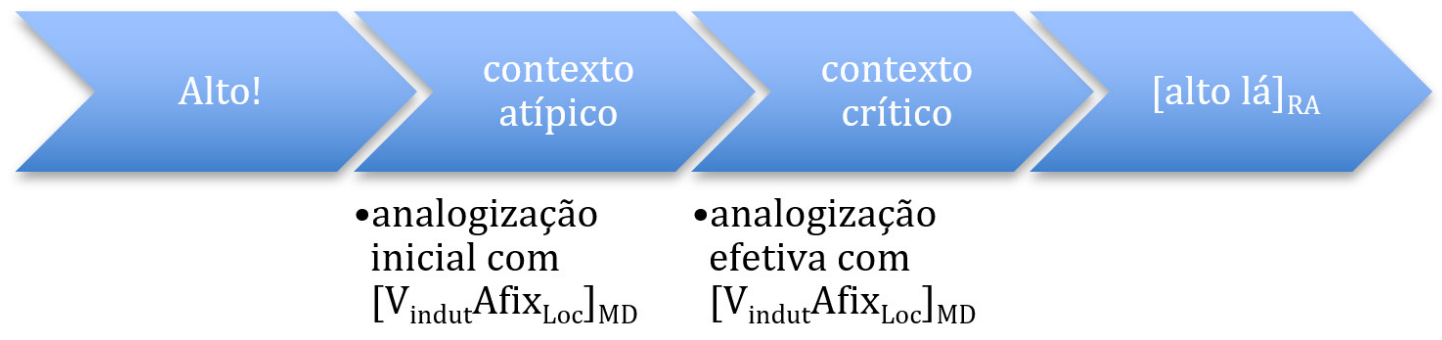


Por intermédio da Figura 3, demonstramos a combinação dos micropassos contextuais, focalizando a etapa de transição de contexto atípico a crítico, com o mecanismo de analogização, atuante também nesses dois estágios. Destacamos o contexto inicial, em que alto ocorre como frase nominal interjetiva, instanciada em situações de sentido bélico, e o contexto final, concernente à fase de isolamento, em que se convencionaliza [alto lá $]_{\mathrm{RA}}$. Assim, como se detecta pela Figura 3, nosso objeto de pesquisa é consequente de uma mescla de fatores, de natureza distinta, que convergem para uma construcionalização gramatical específica.

\section{CONSIDERAÇÕES FINAIS}

A pesquisa da construcionalização do $\mathrm{MD}$ [alto lá $]_{\mathrm{RA}}$ no português ratifica que a mudança linguística é resultante de uma série de motivações de distinta natureza, operantes em momentos específicos na história da língua e por mecanismos diversos. Motivações histórico-sociais, cognitivas e estruturais, como os micropassos contextuais e a analogização, concorreram para a convencionalização desse novo membro do paradigma dos $\mathrm{MD}$ da língua.

De outra parte, uma vez convencionalizada como microconstrução, [alto lá $]_{\mathrm{RA}}$ concorre para reconfiguração do esquema $\left[\mathrm{V}_{\text {indut }} \mathrm{Afix}_{\mathrm{Loc}}\right]_{\mathrm{MD}}$. A rede construcional dos marcadores discursivos formados por verbos indutores e afixoides de origem locativa, apresentada por Teixeira (2015), é reconfigurada de modo que o slot nuclear da macroconstrução passa a instanciar outras categorias de elementos indutores além da verbal. Sendo assim, devido à reconfiguração $\left[\mathrm{V}_{\text {indut }} \mathrm{Afix}\right]_{\mathrm{MD}}>[\text { Indut Afix }]_{\mathrm{MD}}$, novos links são criados em que não só verbos como também frases nominais, advérbios etc., caracterizados como indutores, passam a compor a subparte nuclear da construção. Relacionamos essa reconfiguração à expansão host-class, proposta por Himmelmann (2004), posto que os afixoides passam a associar-se a novos elementos da macroclasse indutora com os quais não mantinham vinculação sintático-semântica.

\section{REFERÊNCIAS}

ANDERSEN, H. Actualization and the (uni)directionality. In Henning Andersen (ed). Actualization: Linguistic change in progress. Amsterdam: Benjamins, 2001, p. 225-248.

BLUTEAU, R. Vocabulário portuguez \& latino. Lisboa: Officina de Pascoal da Sylva, 1716. BOOIJ, G. Morphology in construction grammar. In: HOFFMANN, T.; TROUSDALE, G. (eds.). The oxford handbook of construction grammar. Oxford: Oxford University Press, 2013, p.255-273. 
BYBEE, J. Language, usage and cognition. New York: Cambridge University Press, 2010.

BYBEE, J. Language change. Cambridge: Cambridge University Press, 2015.

CROFT, W. Radical construction grammar: syntactic theory in typological perspective. Oxford: Oxford University Press, 2001.

DIEWALD, G. A model for relevant types of contexts in grammaticalization. In: WISHER, Ilse; DIEWALD, G. (eds). New reflections on grammaticalization. Amsterdan: John Benjamins, 2002, p.103-120.

DIEWALD, G. Contexts types in grammaticalization as constructions. In: Special volume 1: Constructions all over - case studies and theoretical implications. Dusseldorf, 2006. Disponível em: www. constructions-online.de:009-4-6860. Acesso em: 10 de mar. 2019.

DIEWALD, G; SMIRNOVA, E. "Paradigmatic integration": the fourth stage in an expanded grammaticalization scenario. In: DAVIDSE, K. et al (eds). Grammaticalization and language change - new reflections. Amsterdam/Philadelphia: John Benjamins, 2012, p.111-131.

FISCHER, O. Grammaticalization as analogically driven change? In: Vienna English Working Papers, vol. 18, n. 2, 2009. p.3-23.

GOLDBERG, A. Constructions: a construction grammar approach to argument structure. Chicago: University of Chicago Press, 1995.

GOLDBERG, A. Constructions at work: the nature of generalization in language. Oxford: Oxford University Press, 2006.

GOLDBERG, A. Explain me this: creativity, competition and the partial productivity of constructions. Princeton and Oxford: Princeton University Press, 2019.

HEINE, B.; KALTENBÖCK, G.; KUTEVA, T. On the rise of discourse markers. Researchgate. Preprint, june, 2019, DOI: 10.13140/RG.2.2.31703.73129. Disponível em: htps://www.researchgate.net/publication/333783353. Acesso em: 27 de jun. 2019.

HILPERT, M. Construction grammar and its application to English. Edinburgh: Edinburgh University Press, 2014.

HIMMELMANN, N. P. Lexicalization and grammaticalization: opposite or orthogonal? In: BISANG, HIMMELMANN \& WIEMER (eds.). What makes grammaticalization? A look from its fringes and its components. Berlin: Mouton de Gruyter, 2004, p.21-42.

LAKOFF, G.; JOHNSON, M. Metaphors we live by. Chicago: The University of Chicago Press, 2003.

LANGACKER, R. Cognitive Grammar: A basic introduction. New York: Oxford University Press, 2008.

OLIVEIRA, M. R.; ARENA, A. B. O viés funcional do pareamento simbólico função < > forma na abordagem construcional da gramática. Soletras, no. 37, p. 30-58, 2019.

OLIVEIRA, M. R.; CEZARIO, M. M. (orgs). Funcionalismo linguístico: vertentes e diálogos. Niterói: Editora da UFF, 2017. 
ROSA, F. S. L. A mesoconstrução marcadora discursiva refreador-argumentativa: uma análise cognitivo-funcional. 216 fls. Tese (Doutorado em Estudos de Linguagem) Instituto de Letras, Universidade Federal Fluminense, Niterói: RJ, 2019.

ROSÁRIO, I. C.; OLIVEIRA, M. R. Funcionalismo e abordagem construcional da gramática. Alfa, 2016, n. 60, v. 2, p. 233-259.

TEIXEIRA, A. C. M. A construção verbal marcadora discursiva VLoc ${ }_{M D}$ : uma análise funcional centrada no uso. 297 fls. Tese (Doutorado em Estudos de Linguagem) Instituto de Letras, Universidade Federal Fluminense, Niterói: RJ, 2015.

TRAUGOTT, E. Grammaticalization, constructions and the incremental development of language: Suggestions from the development of degree modifiers in English. In Regine Eckardt, Gerhard Jäger, and Tonjes Veenstra (eds). Variation, Selection, Development-Probing the Evolutionary Model of Language Change. Berlin/New York: Mouton de Gruyter, 2008. p. 219-250.

TRAUGOTT, E; DASHER, R. Regularity in semantic change. Cambridge: Cambridge University Press, 2005.

TRAUGOTT, E. C.; TROUSDALE, G. Constructionalization and constructional changes. Oxford: Oxford University Press, 2013. 